\title{
Análise da Importância do Projeto na Concepção de Serviços: Estudo do Caso da Coleta Seletiva em Escolas do Município do Rio de Janeiro realizada pela Companhia de Limpeza Urbana (Comlurb)
}

\author{
Gilberto Luiz Vimercati Neto (UFRJ) gilbertovimercati@ig.com.br \\ Vivian Helena Monteiro de Mattos (IBMEC) vivian_mattos@hotmail.com
}

\begin{abstract}
Resumo
Este trabalho se propõe a definir o que é projeto de serviço e analisar o seu papel como fator estratégico fundamental dentro da concepção de um novo serviço. Para isto, foi estudado o caso do serviço de coleta seletiva em escolas da cidade do Rio de Janeiro realizado pela Companhia Municipal de Limpeza Urbana (Comlurb).
\end{abstract}

Palavras chave: Projeto, Serviços, Coleta Seletiva.

\section{Introdução}

O projeto de serviço, apesar de ser um tema pouco estudado pelo marketing, é o instrumento mais efetivo e eficiente com o qual uma empresa conta para prevenir falhas durante a prestação de um serviço (TAX e STUART, 1997). Adicionalmente, ele permite que a organização possa atingir altos níveis de qualidade e de satisfação do cliente, atingindo seus objetivos e desempenhando sua missão.

A idéia de projeto, no entanto, está originalmente relacionada com o desenho industrial de novos produtos (COVA, 2004). Para que se possa entender o sentido de projeto neste caso é necessário que faça considerações em relação à natureza dos serviços. Serviços se diferenciam de produtos por serem intangíveis, intransportáveis, produzidos e consumidos simultaneamente, por não serem estocáveis, por possuírem um alto nível de contato com o consumidor que avalia não somente o resultado, mas toda a operação (SLACK, 2002). Portanto, projetar um serviço requer atentar para estas condições.

Desta maneira, o objetivo deste trabalho é definir o que constitui o projeto de serviço e apresentar e avaliar um caso onde a atividade de projetar algo, que por definição é imaterial, faz parte da atividade central da empresa.

Assim sendo, foi escolhido como caso de estudo a elaboração e implementação do projeto de coleta seletiva em escolas do município do Rio de Janeiro, realizadas pela Companhia de Limpeza Urbana (Comlurb). As razões que motivaram a escolha foram a pertinência da situação, visto que se trata da oferta de um novo serviço em uma empresa já estabelecida no mercado, a importância do projeto para este caso e, por fim, a disponibilidade das informações.

\section{Revisão do Conceito de Projeto de Serviço}

Projeto, segundo Magalhães (1997) é a tradução mais utilizada no Brasil para o termo design. Desta forma, ele é costumeiramente associado às formas ou ao desenvolvimento de um produto e muito pouco referido a serviços. O conceito de projeto de serviço utilizado neste trabalho, tal qual definido por Cova (2004), é o de que projetar um serviço é dar forma a relações entre pessoas, entre objetos e entre pessoas. Contribui para reforçar este sentimento a definição de Slack (2002, p.134) de que "projeto é a atividade que molda a forma física e o propósito tanto de produtos e serviços, como dos processos que os produzem". 
Estas acepções do termo se encaixam na nova perspectiva de que o projeto não deve ser feito apenas por questões estéticas, mas deve considerar a promoção do bem-estar social, contribuindo para que a empresa cumpra sua missão. Desta forma, o projeto adquire um valor dentro da estratégia organizacional.

Assumindo que as pessoas desejam os benefícios gerados pelos produtos adquiridos ou pelos serviços contratados, pode-se considerar o projeto como um meio para a satisfação das necessidades e desejos dos indivíduos. Assim sendo, ele cria valor para os consumidores que se dispõem a pagar mais para obter um determinado produto ou serviço, permitindo que as empresas aumentem suas receitas. O projeto, neste caso, é importante para a diferenciação da empresa de seus concorrentes (MAGALHÃES, 1997). Sob a ótica da empresa, projetar um serviço significa definir um conjunto apropriado de componentes físicos e conceituais (GOLDSTEIN et al., 2002).

O projeto adquire importância pois é por meio deste que as organizações poderão definir o conceito que estará sendo vendido através da prestação do serviço e garantir que as características do serviço atendam as necessidades dos consumidores e os interesses da própria organização.

Mas para que o serviço seja realizado conforme foi projetado, é necessário que funcionários e clientes entendam e compartilhem o conceito que o serviço oferece. Assim, para que ele possa gerar benefícios à empresa, é necessário que sua elaboração e implementação considere os aspectos fundamentais de sua inter-relação com o usuário.

Baxter (1998) classifica os fatores determinantes para o sucesso ou fracasso de um lançamento (de um serviço) em três grupos: orientação para o mercado, estudos de viabilidade e especificação e qualidade do desenvolvimento. Um projeto que apresente estes três fatores possuirá cinco vezes mais chances de ser bem sucedido. O caso em estudo, como será mostrado, revela uma aplicação estratégica do conceito de projeto, sendo visível a presença destes três fatores.

\section{Visão geral da coleta seletiva e da Reciclagem no Brasil}

Entende-se por coleta seletiva o processo por meio do qual os componentes recicláveis do lixo são acondicionados separadamente por componente ou grupo de componentes, na própria fonte geradora, e coletados de maneira apropriada para que possam ser reciclados posteriormente. A coleta seletiva não deve ser confundida com a seleção ou triagem do lixo, que constitui uma etapa anterior e consiste em separar os materiais de diferentes características químicas, que pode ocorrer na própria fonte geradora ou nas usinas de triagem. A seleção ou triagem do lixo facilita a coleta seletiva (COMLURB, 2005).

Para se entender a importância da coleta seletiva, é necessário compreender a importância da reciclagem para a sociedade. A produção de bens industrializados é fonte de riqueza para as sociedades modernas, em especial para as grandes cidades. Ocorre, no entanto, que dela ou do consumo dos bens produzidos são originados resíduos sólidos urbanos que precisam ser dispostos. A reciclagem contribui para a minimização do problema de gerenciamento destes resíduos, sendo o seu valor mais social do que econômico (PIMENTEIRA, 2002). Isto ocorre porque para muitos materiais o valor economizado e a qualidade obtida pela reciclagem não são superiores ao depósito do material em aterros. Mas, nestes caso, se forem considerados os benefícios sociais obtidos por meio da reciclagem, a avaliação sobre a relevância desta atividade pode ser alterada. 
Para que a reciclagem seja útil à sociedade, é preciso que ela faça parte de um sistema integrado por triagem, coleta seletiva e reciclagem (PIMENTEIRA, 2002). A coleta seletiva é tão importante para a reciclagem dos materiais que muitas vezes ela é confundido com a própria. Desta forma, convém estabelecer que a reciclagem é a transformação de materiais de forma a propiciar que estes sejam reaproveitados na produção de novos produtos, sendo bastante favorecida pela coleta seletiva.

No Brasil, os percentuais de consumo reciclado vêm crescendo. Em 2003, segundo a Associação Brasileira de Embalagens - ABRE (2005), foram reciclados 47\% das folhas de flandres consumidas, $45 \%$ do total de vidro que circula no mercado nacional, $43 \%$ das embalagens de PET pós-consumo, 35\% do consumo doméstico de alumínio 21\% dos plásticos rígidos e filmes e $20 \%$ das embalagens compostas (tipo longa vida). A Figura 1 ilustra a comparação entre estes percentuais de consumo reciclado para cada um dos materiais mencionados.

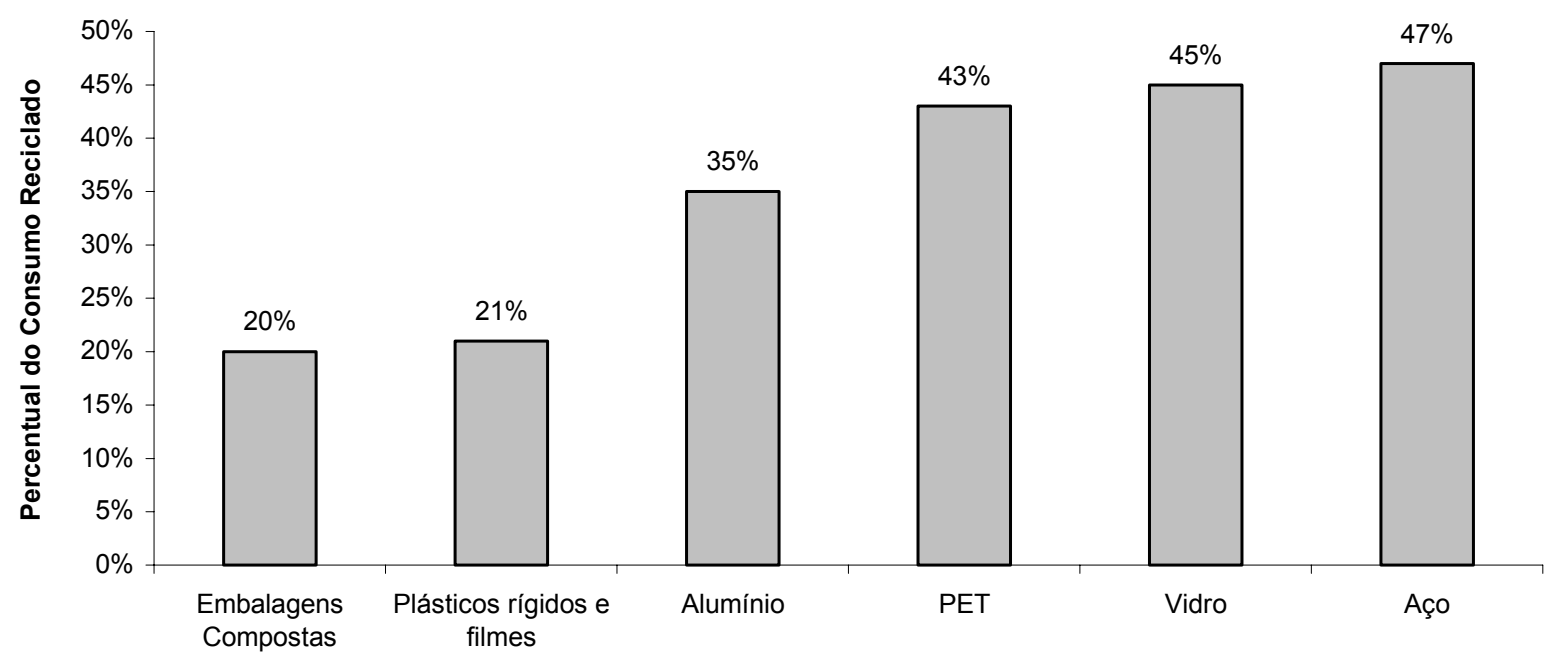

Figura 1 - Percentual do consumo reciclado dos principais componentes do lixo em 2003

Para alguns destes, o percentual de reciclagem no Brasil impressiona, alcançando os mesmos níveis de países desenvolvidos. Adotando o ano de 2001 para efeito de comparação com o desempenho de outros países, ainda que os índices brasileiros variem um pouco em relação aos registrados em 2003, pode-se observar que o país possuía uma boa média de reciclagem para a maioria dos materiais.

O desempenho do país foi superior ao de França, Espanha e Portugal para quase todos os materiais, exceto para a reciclagem de papel e papelão, cujo percentual foi bem próximo.

O único grupo cujo percentual de reciclagem destoa dos demais é o de resíduos orgânicos. Para estes, a reciclagem alcança apenas $1,5 \%$ da produção nacional, sendo este percentual inferior a um terço do registrado em países vizinhos da América do Sul, como a Argentina, e bem abaixo dos $59 \%$ obtidos pelos Estados Unidos.

A Tabela 1 apresenta a comparação do percentual brasileiro de reciclagem para os materiais citados. 


\begin{tabular}{|c|c|c|c|c|c|c|}
\hline País & $\begin{array}{l}\text { Plásticos } \\
\text { Rígidos e } \\
\text { Filmes }\end{array}$ & $\begin{array}{l}\text { Papel e } \\
\text { Papelão }\end{array}$ & Latas de Aço & Vidro & $\begin{array}{l}\text { Embalagens } \\
\text { de Alumínio }\end{array}$ & $\begin{array}{l}\text { Resíduos } \\
\text { Orgânicos }\end{array}$ \\
\hline Brasil & $17,5 \%$ & $43,9 \%$ & $45 \%$ & $44 \%$ & $87 \%$ & $1,5 \%$ \\
\hline Estados Unidos & $13,5 \%$ & $55 \%$ & $59 \%$ & $22 \%$ & $49 \%$ & $59,3 \%$ \\
\hline Argentina & $5 \%$ & $10 \%$ & $15 \%$ & ND & $60 \%$ & $\begin{array}{c}\text { Menos que } \\
5 \%\end{array}$ \\
\hline Chile & $\begin{array}{c}\text { Menos que } \\
5 \%\end{array}$ & ND & $10 \%$ & $5 \%$ & ND & ND \\
\hline Colômbia & $6 \%$ & $35 \%$ & ND & $16 \%$ & $38 \%$ & ND \\
\hline Suécia & $17,60 \%$ & $43,70 \%$ & $62 \%$ & $87,50 \%$ & ND & ND \\
\hline República Tcheca & $27 \%$ & $62 \%$ & $35 \%$ & $57 \%$ & ND & ND \\
\hline Polônia & $7 \%$ & $38 \%$ & ND & $13 \%$ & $15 \%$ & ND \\
\hline Espanha & $17 \%$ & $52,70 \%$ & $45 \%$ & ND & ND & ND \\
\hline Portugal & ND & $16 \%$ & ND & ND & $7 \%$ & ND \\
\hline França & $15 \%$ & $45 \%$ & ND & ND & $20 \%$ & ND \\
\hline
\end{tabular}

ND - Não disponível

Fonte: CEMPRE, Tetra Pak Américas, Pro Europe e enviroment Protection Agency (2001) em ABRE (2004)

Tabela 1 - Percentuais de consumo reciclado comparados por país

Além dos benefícios ambientais oferecidos, no Brasil há também a questão social. A coleta seletiva de materiais para reciclagem realizada por cooperativas de catadores constitui fonte de renda para muitas pessoas. A Tabela 2 apresenta os valores pagos por tonelada de alguns materiais na cidade do Rio de Janeiro.

\begin{tabular}{lc}
\hline \multicolumn{1}{c}{ Material } & R\$ / ton. \\
\hline Lata de alumínio & 800 \\
PET & 200 \\
Papel branco & 200 \\
Bateria & 200 \\
Plástico duro & 170 \\
Papelão & 100 \\
Jornal & 100 \\
Ferro & 40 \\
Lâmpada Fluorescente & 30 \\
Vidro & 20 \\
\hline Fonte: Comlurb (2005) &
\end{tabular}

Tabela 2 - Preços pagos pela tonelada de material na cidade do Rio de Janeiro

O aspecto social e a gradativa conscientização da sociedade a respeito da necessidade de reciclagem deverão contribuir para que os percentuais enumerados anteriormente aumentem. Entretanto, para que isso ocorra de fato, será necessária uma estrutura capaz de suportar este aumento. E porque a coleta seletiva é parte desta estrutura, a boa elaboração do seu projeto é fundamental. Uma situação onde ele pode ser bem estudado é o caso da elaboração e implementação de coleta seletiva para escolas do município do Rio de Janeiro.

\section{Projeto de coleta seletiva para escolas no município do Rio de Janeiro}

A coleta seletiva depende de três fatores: mercado, tecnologia e informação. Em relação ao mercado, constata-se a existência de grande potencial para este serviço no município do Rio de Janeiro. Para uma população estimada em 6 milhões de habitantes em 2004 (IBGE, 2004), o volume total de lixo coletado no mesmo ano (excluindo lixo hospitalar) foi de 2,9 milhões de toneladas (COMLURB, 2005), o equivalente a uma média diária de 1,3 quilo de lixo por habitante por dia. 
Quanto à tecnologia, este serviço requer que sejam feitas a triagem e a classificação dos materiais por tipo antes da coleta propriamente dita. Além disso, adaptações no acondicionamento e no transporte do lixo devem ser feitas de maneira que esta separação seja mantida até que seja entregue nas cooperativas de catadores ou nas usinas de reciclagem. Por fim, o último requisito refere-se à conscientização do usuário. Para que a coleta seletiva seja eficiente, é necessário que os usuários sejam informados de sua realização e da forma como deverão tratar o lixo a partir do momento em que ela estiver implementada.

Além desses aspectos fundamentais à atividade, o projeto deve considerar os objetivos estratégicos da empresa. Baxter (1998) define a estratégia organizacional como uma "ponte" que liga os negócios atuais de uma empresa à sua missão e aos seus objetivos. Este mesmo autor acrescenta que a escolha das alternativas estratégicas será restringida por fatores como pessoal, dinheiro, tempo, conhecimento, habilidades e demais recursos produtivos. Em outras palavras, a especificação de uma atividade dentro de qualquer empresa deve sempre considerar que o resultado do projeto possuirá um papel em sua estratégia organizacional.

A missão da empresa é expressa na sua página na Internet como "conservar a cidade limpa com a manutenção de padrões de qualidade e custos otimizados, com foco na saúde, na educação e preservação ambiental". Sendo assim, os serviços oferecidos por ela devem ter como objetivo a limpeza urbana e devem atender requisitos referentes a qualidade, custo, saúde, educação e meio ambiente. A Figura 2 é uma representação do contexto estratégico considerando o modelo proposto por Baxter (1998).

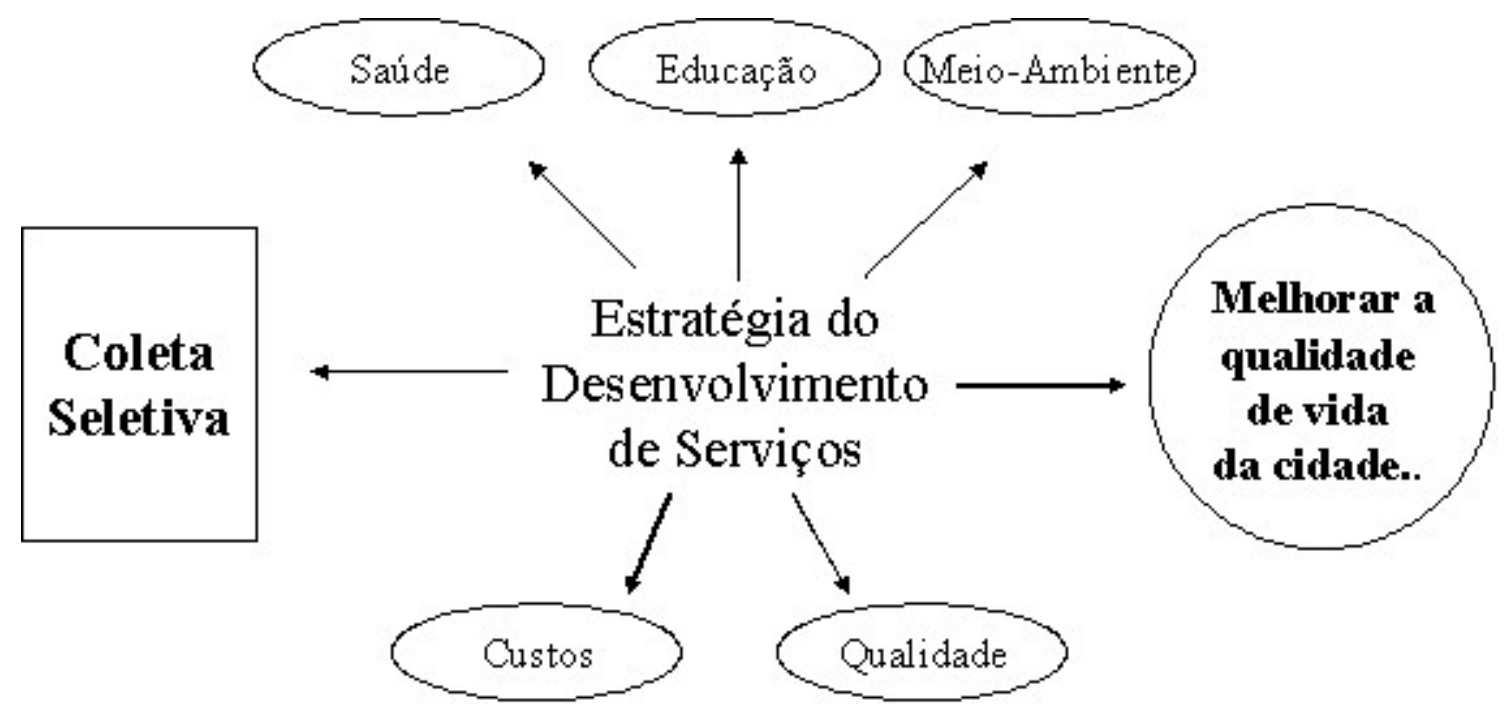

Figura 2 - Representação da estratégia de desenvolvimento de serviços da Comlurb

Assim, a oferta do serviço de coleta seletiva em escolas tem como objetivo preencher uma função que ajude a Comlurb a desempenhar sua missão e contribua para que ela se aproxime de seus objetivos. Considerando os requisitos estabelecidos pela empresa para a prestação de serviços à sociedade, as contribuições da coleta seletiva em escolas para os objetivos da empresa são:

- Implementação de um programa contínuo de educação ambiental;

- Formação de agentes multiplicadores;

- Melhorar a qualidade de vida nas cidades; 
- Diminuir o volume de lixo depositado em aterros;

- Fomentar a produção, em escolas, de materiais recicláveis para as cooperativas de catadores;

- Geração de empregos.

A realização de coleta seletiva em escolas é uma iniciativa desenvolvida pela Comlurb há mais de 10 anos. Ela possui o apoio da Prefeitura do Rio de Janeiro e envolve a participação ativa da sociedade, gerando renda e emprego para catadores, que trabalham em cooperativas administradas por meio de auto-gestão com o apoio técnico da empresa. Outras vantagens incluem: o estímulo à cidadania, a redução do volume de lixo a ser tratado e a conscientização ambiental de jovens e crianças.

Em linhas gerais, o trabalho desenvolvido pela empresa consiste na mobilização da comunidade da escola em torno de um objetivo comum de preservação ambiental. Desta forma, esta comunidade será gestora e responsável pelo projeto, sendo assessorada tecnicamente pela empresa. A partir da campanha de comunicação do serviço, pais, alunos, professores e funcionários se tornam vetores da implementação do projeto, realizando a triagem inicial do lixo no momento em que descartam os resíduos separadamente nas lixeiras apropriadas.

O lixo é acondicionado em embalagens plásticas transparentes específicas para este tipo de coleta e recolhido pela Comlurb ou diretamente pelas cooperativas por meio dos catadores de lixo. Caso o lixo seja coletado pela empresa, há uma posterior transferência deste material para as cooperativas, que serão responsáveis por encaminhá-lo paras as usinas de reciclagem.

A elaboração do projeto começa com a identificação, por parte da própria escola, da necessidade ou demanda deste serviço. Depois de solicitado, o projeto é implementado pela própria escola por meio do Comitê Interno de Coleta Seletiva (CICS) que contará com o apoio técnico da Comlurb e com a participação das cooperativas de catadores. Durante todo o procesos, a participação da comunidade será estimulada e valorizada, pois ela é fundamental para o sucesso da coleta seletiva.

A implementação do projeto possui três etapas: conscientização, operacionalização e avaliação. Na primeira etapa, é realizado um trabalho de comunicação, por meio de palestras, reuniões, e campanhas educacionais e informativas, cujo objetivo é a conscientização de professores, pais, alunos e funcionários, visando a atender o requisito de informação exigido pelo serviço. Durante esta fase serão definidos os CICS, que contarão com representantes de todos os envolvidos. A função dos CICS será a de disseminar a idéia e a importância da coleta, bem como acompanhar o processo de implementação do projeto.

Na segunda etapa, é realizado um estudo sobre a viabilidade técnica-operacional da execução do projeto. Nesta fase são coletadas informações sobre a escola e sobre o lixo produzido por ela. É efetuado um levantamento do volume de recicláveis produzidos pela escola para identificação da quantidade, composição e qualidade. Além disto, o espaço físico e a infraestrutura disponíveis são avaliados quanto às dimensões e localização. $\mathrm{O}$ meio e a forma de armazenamento são selecionados de forma a se adequarem às condições de espaço analisadas anteriormente. Por fim, os integrantes dos CICS têm suas funções definidas, sendo nomeados os responsáveis pela coleta dos materiais e pela fiscalização da implementação do projeto e é definida a participação dos catadores na operação de coleta do material reciclável, com o aval da Comlurb.

$\mathrm{Na}$ última etapa, a implementação e a execução do projeto serão avaliadas. Para isto, são 
formadas equipes específicas para este propósito. Elas coletarão informações que serão utilizadas para realimentar o processo, corrigindo falhas e propondo melhorias. Adicionalmente, serão coletados dados estatísticos que ilustrem o desempenho do serviço. Nesta fase, as atividades de conscientização continuam ou voltam a ser realizadas com o intuito de enfatizar a importância da adesão da comunidade ao projeto.

\section{Conclusões}

Apesar de sua natureza intangível, a importância do projeto para a prestação de serviços é tão grande quanto para o desenvolvimento de produtos. Ignorar ou especificar equivocadamente as necessidades dos usuários pode originar serviços que não atendam às exigências do mercado e, em conseqüência disto, não alcancem seus objetivos dentro da estratégia da empresa que os elaborou.

A elaboração do projeto de coleta seletiva permite que esta englobe três fatores que aumentam as suas chances de sucesso. Primeiro, o serviço se torna orientado para o mercado, no caso a comunidade da escola. Por ser exaustivamente divulgado e discutido dentro da escola antes de sua implementação, a comunidade tem a oportunidade de receber um serviço projetado inteiramente para as suas necessidades. Segundo, são realizados minuciosos estudos de viabilidade e especificação que consideram as características da escola e sua infra-estrutura, justificando o serviço e criando condições para que ele possa ser executado. Por fim, há uma grande preocupação com a qualidade do desenvolvimento, existindo equipes específicas para avaliar o serviço e fornecer informações que permitam corrigir ou melhorar o desempenho.

Dentro do contexto estratégico da empresa, o projeto contribuiu para que o serviço atingisse seus objetivos, atendendo os requisitos definidos pela organização em sua missão (saúde, educação, meio ambiente, custo e qualidade). Isto ocorre porque a coleta seletiva quando devidamente projetada e implementada estimula a reciclagem, reduz a quantidade de lixo gerado, preserva o meio-ambiente, diminui os custos da coleta tradicional, gera emprego e renda para catadores de lixo e contribui para a educação ambiental de jovens e crianças.

\section{Referências}

ASSOCIAÇÃO BRASILEIRA DE EMBALAGENS (2004) - Reciclagem no Brasil e no Mundo. Disponível: http://www.abre.org.br/meio_reci_brasil.php

BAXTER, M. (1998) - Projeto de Produto. Edgard Blucher. São Paulo.

COMLURB (2005) - Guia de Reciclagem. Disponível: http://www.rio.rj.gov.br/comlurb. Acessado em: 15 de Maio de 2005.

COVA, V. (2004) - "Le Design des Services". Décisions Marketing. Vol. 34, (Abril - Junho de 2004), p.29-40. Paris.

GOLDSTEIN, S. M. et al. (2002) - "The service concept: the missing link in the service design research?". Journal of Operations Management. Vol.20, $\mathrm{n}^{\circ} 2$; pg. 121. Columbia.

IBGE (2004) - Estimativa de População para os municípios brasileiros para $1^{\circ}$ de Julho de 2004. Disponível: http://www.ibge.gov.br. Acessado em: 15 de Maio de 2005.

MAGALHÃES, C. (1997) - Design Estratégico - integração e ação do design industrial dentro das empresas. CNI-SENAI-CETIQT. Rio de Janeiro.

PIMENTEIRA, C. A. P (2002) - Aspectos Sócio-Econômicos da Gestão de Resíduos Sólidos na Cidade do Rio de Janeiro - uma Análise Insumo Produto. Tese de Mestrado. COPPE/UFRJ, Rio de Janeiro, RJ.

SLACK,N.; CHAMBERS, S.; HARLAND, C.; HARRISON, A \& JOHNSTON, R. (2002) - Administração da Produção. Atlas. $2^{a}$ Edição. São Paulo.

TAX, S. S. \& STUART, I. (1997) - "Designing and implementing new services: the challenges of integrating new service systems". Journal of Retailing. Vol. 73 (1997), pp. 105-134. 